\title{
Uso da avaliação por portfólio no ensino supeior militar: uma experiencia.
}

El uso de la evaluación por portafolio en la enseñanza militar superior: una experiencia.

The use of portfolio evaluation in higher military education: an experience

Hércules Guimarães Honorato

Escola Naval - Rio de Janeiro, Brasil. hghhhma@gmail.com 


\section{Resumo}

Este artigo é uma pesquisa bibliográfica exploratória, de abrangência qualitativa, que teve por objetivo refletir sobre o sentido da avaliação no ensino superior militar, bem como apresentar algumas reflexões iniciais a partir de uma experiência sobre o uso de portfólio como alternativa de avaliação do processo de ensino e aprendizagem. O cenário do experimento foi a Escola Naval, instituição situada na Cidade do Rio de Janeiro. A disciplina escolhida para a realização da experiência foi a de Cultura Organizacional Militar, porque teve o apoio de sua docente e a turma era pequena, doze alunas. 0 instrumento de coleta de dados foi uma entrevista semiestruturada com a referida professora. 0 portfólio é uma coleção dos trabalhos realizados pelos estudantes, de construção de conhecimentos de forma contínua e reflexiva, além de uma ferramenta estratégica inovadora de aprendizagem e de avaliação, que procura, por meio de diálogos e de um acompanhamento das atividades propostas, buscar caminhos para o que não foi ainda aprendido pelo aluno, superando as tradicionais avaliações por provas. 0 ensino superior militar é considerado de qualidade, porém ainda utiliza a avaliação excludente e hierarquizadora, e os seus docentes são profissionais qualificados e que têm uma relação de força e poder perante os seus alunos, tanto na relação de sala de aula como na transmissão de conteúdos. Ao final, essa experiência foi considerada importante e positiva, pois a docente ousou, desafiou e estimulou suas alunas a construírem conhecimento através dos trabalhos desenvolvidos dentro e fora da sala de aula, e a se autoavaliarem. O uso do portfólio ainda não é muito estudado e explorado no Brasil, por isso mesmo espera-se que este estudo seja relevante no desenvolvimento de alternativas formativas inovadoras, saindo de uma visão pontual da avaliação apenas como medida classificatória e excludente.

\section{Resumen}

Este artículo es resultado de una búsqueda bibliográfica exploratoria, de alcance cualitativo, que tuvo como objetivo reflexionar sobre el sentido de la evaluación en la educación superior militar, así como presentar algunas consideraciones iniciales a partir de una experiencia sobre el uso del portafolio como alternativa de evaluación del proceso de enseñanza y aprendizaje. El escenario del experimento fue la Escuela Naval, institución ubicada en la Ciudad de Rio de Janeiro. La disciplina escogida para la realización de esta experiencia fue la Cultura Organizacional Militar, porque tuvo el apoyo de la docente y la clase era pequeña, doce alumnas. El instrumento de colecta de datos fue una entrevista semiestructurada con la referida profesora. El portafolio es una colección de trabajos realizados por los estudiantes, de construcción de conocimientos de 
forma continua y reflexiva, así como una herramienta estratégica innovadora de aprendizaje y evaluación, que busca, a través del diálogo y el seguimiento de actividades propuestas, encontrar caminos para lo que aún no fue aprendido por el alumno, superando las tradicionales pruebas de evaluación. La educación militar superior es considerada de calidad, pero sigue utilizando la evaluación excluyente y jerarquizada, sus profesores son profesionales calificados que tienen una relación de fuerza y poder ante sus alumnos, tanto en la relación en el salón de aula como en la transmisión de contenidos. Al final, esta experiencia fue considerada importante y positiva, porque la profesora se atrevió, desafió y animó a sus alumnas para que construyesen conocimiento a través de los trabajos desarrollados dentro y fuera del aula y a su autoevaluación. El uso del portafolio aun no es muy estudiado o explorado en Brasil, por eso se espera que este estudio sea relevante en el desarrollo de alternativas de formación innovadoras, saliendo de una visión puntual de la evaluación como medida clasificatoria y excluyente.

\section{Abstract}

This article is an exploratory literature search, qualitative scope, which aimed to reflect on the meaning of evaluation in higher military education as well as present some initial considerations from an experience on using the portfolio as an alternative assessment teaching and learning process. The stage of the experiment was the Naval Academy, an institution located in the City of Rio de Janeiro. The discipline chosen for the realization of this experience was the organizational culture Military, because I had the support of the teacher and the class was small twelve students. The data collection instrument was a semistructured interview with the aforementioned teacher. The portfolio is a collection of works by students, building knowledge of continuous and thoughtful way, as well as an innovative strategic tool for learning and assessment, which seeks, through dialogue and monitoring of proposed activities, find ways to what he was not learned by the student, overcoming the traditional assessment tests. Higher military education is considered quality, but still uses the exclusive and hierarchical evaluation, teachers are qualified professionals who have a relationship of strength and power to his students, both in the relationship in the classroom classroom and in the transmission of content. In the end, this experience was deemed important and positive, because the teacher dared challenged and encouraged his students to them to build knowledge through the work done inside and outside the classroom and his self-assessment. The use of portfolio still not well studied or explored in Brazil, so it is expected that this study is relevant to the development of innovative training alternatives, leaving a timely vision of evaluation as qualifying and exclusionary measure. 


\section{Palavras-Chave}

Avaliação, Ensino superior militar, Portfólio.

\section{Palabras Clave}

Evaluación, Enseñanza superior militar, Portafolio.

\section{Keywords}

Evaluation, Higher Military Training, Portfolio.

\section{Introdução}

“Saber que ensinar não é transferir conhecimento, mas criar as possibilidades para a sua própria produção ou a sua construção."

(Paulo Freire).

O ser humano não nasce pronto para trilhar o seu caminho de vida, ele necessita dos seus pares para a sua formação. A gênese da formação sóciopolítica do homem encaminha-se por intermédio da educação, uma mediação que vai ser desenvolvida para a sua autonomia e para a sua integração social. Libâneo (2005, p.23) argumenta que não existe uma natureza humana universal. Os sujeitos são construídos socialmente e vão formando sua identidade, "de modo a recuperar sua condição de construtores de sua vida pessoal e seu papel transformador" dessa sociedade.

Nesse caminho, a pedagogia - como ciência dessa educação - ocupa-se das tarefas de formação humana em contextos determinados por marcos espaciais e temporais, cabendo ao professor enfrentar essa realidade educativa imersa em perplexidades, crises, incertezas, pressões sociais e até econômicas, além de utopias educativas. Assim, a pedagogia "há de se abrir para que toda a contribuição ajude a explicitar as peculiaridades do fenômeno educativo e do ato de educar em um mundo em mudança" (Libâneo, 2005, p. 18). Na sequência da relação do professor-aluno temos o ensino e a aprendizagem, sendo que a avaliação seria o acompanhamento desse processo acadêmico. É importante que o professor "possa criar, e verificar no uso, atividades diversas que ensejem avaliação de processos de aquisição de conhecimentos e desenvolvimentos de atitudes, de formas de estudo e trabalho, individual ou coletivamente [...]" (Gatti, 2003, p.99), procurando retirar o efeito negativo dos exames e provas pontuais e excludentes, pois "a avaliação não é uma tortura medieval" (Perrenoud, 1999, p.9).

O ensino superior militar nas Forças Armadas brasileiras, composto pela Escola Naval (EN), Academia Militar das Agulhas Negras (AMAN) e Academia da Força Aérea (AFA), tem como tarefa principal a formação dos seus oficiais para os primeiros postos da carreira militar. Os oficiais formados obtêm a certificação 
em áreas específicas do seu emprego, tornando-se, ao término da graduação, bacharéis em "Ciências Militares", com reconhecimento pelo Ministério da Educação (MEC). Porém, o sistema avaliativo do seu ensino ainda está ancorado na avaliação somativa tradicional, sendo as provas e testes seus pontos de checagem da aprendizagem durante o ano letivo.

Em 2014, em uma disciplina específica da matriz curricular da EN, denominada "Cultura Organizacional Militar" (COM), a professora resolveu fazer a experiência de utilizar uma alternativa pedagógica, que teve como foco a avaliação formativa na construção desse conhecimento escolar, colocando as Aspirantes como responsáveis por seu processo de aprendizagem. Assim, o portfólio foi utilizado pela primeira vez no meio acadêmico militar. O objetivo deste estudo é refletir sobre o sentido da avaliação em uma instituição de ensino superior (IES) militar, bem como apresentar algumas considerações iniciais a partir de uma experiência sobre o uso de portfólio como alternativa de avaliação do processo de aprendizagem. Espera-se que este estudo seja relevante no desenvolvimento de outras formas de avaliação em uma graduação militar, como alternativa formativa na relação ensino-aprendizagem e na construção da relação professor-aluno, procurando sair da tradicional avaliação utilizada apenas como medida classificatória e excludente.

Para uma melhor compreensão do que foi pretendido, o presente artigo está organizado em três seções principais, além da Introdução e das Considerações Finais. A primeira descreve os principais conceitos envolvidos na temática de avaliação, e apresenta como está sendo efetivada a avaliação da aprendizagem no ensino superior militar. A segunda parte trata especificamente do portfólio, seu conceito, seus óbices e potencialidades verificados em pesquisas no ensino superior. A última seção apresenta a experiência realizada na Escola Naval, as análises do instrumento de coleta de dados e os principais achados verificados.

\section{Metodologia}

Este texto é uma pesquisa bibliográfica exploratória, que segundo Gil (2009) tem por finalidade proporcionar uma visão geral do que vai ser estudado, principalmente quando o tema é pouco explorado. A abordagem metodológica de investigação adotada nesta pesquisa foi qualitativa, que rejeita a neutralidade do pesquisador, com ênfase na interpretação e na motivação que movem os sujeitos e que dão significado à realidade estudada, porém seus achados não podem ser generalizados (Ivenicki \& Canen, 2016). A coleta de dados foi descritiva e contou com uma entrevista semiestruturada com a professora responsável pelo uso do portfólio na instituição em tela. 


\section{Referenciais teóricos}

\section{Avaliação da "Ensinagem": Avaliações somativa e formativa}

Em primeiro lugar é preciso esclarecer o neologismo ensinagem, um termo que foi "adotado para significar uma situação da qual necessariamente decorra aprendizagem, sendo a parceria entre professor e alunos a condição fundamental [...]" (Anastasiou, 2004, p.15). O que se desejou ao introduzir o termo na discussão foi desvelar que a ação do ensinar do professor tem que ter retorno no aprender do aluno, em um processo contratual, que Perrenoud (1999) citou como "contrato didático", uma parceria implícita ou explícita na construção do conhecimento escolar, decorrentes de ações efetivas em sala de aula ou até mesmo fora do chão da escola.

O caminhar pela construção de um sujeito autônomo, histórico e social tem na prática educativa uma possibilidade de propiciar seu crescimento, transitando pela escola e pelo contrato didático, que passa obrigatoriamente pelo ensino e aprendizagem e continua na avaliação como "um ato de investigar a qualidade do seu objeto de estudo, [...] na obtenção dos resultados desejados e definidos, e não de quaisquer resultados que sejam possíveis" (Luckesi, 2011, p.150, grifo do autor).

O que se procura e se deseja na avaliação é acompanhar os processos de aprendizagem escolar do aluno, o que Gatti (2003, p.99) assevera ser "uma atividade contínua e integrada às atividades de ensino". Segundo Perrenoud (1999, p. 11, grifo do autor), a avaliação "é tradicionalmente associada, na escola, à criação de hierarquias de excelências. Os alunos são comparados e depois classificados em virtude de uma norma de excelência [...]".

Avaliar não é medir, porém, como descreve Perrenoud (1999, p.11), a avaliação "regula o trabalho, as atividades, as relações de autoridade e a cooperação em aula e, de uma certa forma, as relações entre a família e a escola ou entre profissionais da educação". A avaliação somativa ou tradicional permite uma certificação da atividade. No caso do estudante, a sua aprovação ou reprovação deve estar em consonância com os resultados obtidos, em uma prova final, por exemplo, ou em uma média de várias notas.

O que se pode verificar é que este tipo de avaliação é classificatória, excludente e que dizem, sobretudo, se o aprendente é melhor ou pior do que seus colegas. Perrenoud (1999, p.12, grifo do autor) trata o assunto da nota como uma mensagem para o aluno de que "ele sabe, mas o que pode the acontecer se continuar assim até o final do ano". A certificação final das aquisições do discente é outra função da avaliação tradicional, pois um diploma garante, sem precisar de novos exames, que seu portador recebeu a formação devida. 
Chueiri (2008, p.62) explica que o contexto escolar já aponta para um esgotamento do modelo teórico-epistemológico, procurando ultrapassar os limites da teoria da métrica e "implementando práticas pedagógicas com novos significados". Para se evitar a lógica excludente dominante em nossa sociedade, procura-se avaliar para qualificar, exigindo que a questão metodológica da avaliação seja tratada com maior pluralidade e flexibilidade, a fim de contemplar as diferenças.

A avaliação formativa ou emancipatória introduz, segundo Perrenoud (1999), uma ruptura na relação professor-aluno, porque se propõe a uma renovação global da pedagogia, da centralização agora sobre o aluno, transformando o professor em criador de situações de aprendizagem, tornando a avaliação verdadeiramente útil em situação pedagógica (Hadji, 2001). Ela auxilia o aluno a aprender e a se desenvolver, colaborando para a regulação das aprendizagens e do desenvolvimento de um projeto educativo. Luckesi (2011, p.210) argumenta que ainda estamos vinculados ao modelo de exames, provas e notas no cotidiano da avaliação, pois nossa prática de "acompanhamento dos educandos em sala de aula ainda tem por base a perspectiva da aprendizagem passada, da classificação, da seletividade, da prática pedagógica autoritária e, por isso, não dialógica". Porém, a prática da avaliação da aprendizagem precisa de um conceitual novo, assim como recursos tecnológicos atuais. Exige também uma nova atitude dos educadores.

\section{0 ensino superior militar}

0 artigo no 83 da Lei de Diretrizes e Bases da Educação Nacional (Lei n. 9394, 1996) estipula que o ensino militar é regulamentado em lei específica, admitida a equivalência de estudos, de acordo com as normas fixadas pelos sistemas de ensino. Cada uma das Forças Armadas tem sua lei específica, mas no trato da avaliação da aprendizagem de seus discentes, em especial o do ensino superior, tem como metodologias específicas as tradicionais provas e testes.

O critério de classificação, que é determinante para toda a carreira militar, vai de encontro a uma avaliação somativa, já mencionada como excludente e hierarquizadora. Só conseguem ser certificados com os diplomas de bacharéis em ciências militares, navais e aeronáuticas, os formados pela AMAN, pela EN e pela AFA, respectivamente. Os formandos têm 0 reconhecimento dos respectivos comandos militares para exercerem cargos e funções em suas organizações militares, independente ou não de terem atingidos o nível mínimo satisfatório de suas capacidades acadêmicas.

O cenário da nossa pesquisa foi a Escola Naval, instituição que está localizada na histórica Ilha de Villegagnon, na cidade do Rio de Janeiro. Esta IES militar tem como missão formar os oficiais da Marinha do Brasil para os postos iniciais da carreira, nos corpos da Armada, Fuzileiros Navais e Intendentes da 
Marinha. Para o cumprimento desse propósito a instituição ministra curso de graduação. O curso regular é de quatro anos. Ao final, o aluno titulado como Aspirante durante o ciclo escolar, passa ao posto de Guarda-Marinha, continuando sua formação no chamado ciclo pós-escolar, que culmina com uma viagem, de cerca de cinco meses pelo exterior, na qual é posto em prática o aprendizado obtido na instituição. Ao término desse último período acadêmico, os jovens se formam e, como segundos-tenentes, são designados para as diversas organizações da Marinha em todo o território nacional - em terra, no mar e nos rios.

\section{O Portfólio}

Como visto anteriormente, avalia-se sempre com o escopo de agir, sendo que a avaliação não é um fim em si mesma, deve ter como pano de fundo a verificação, com reflexão, se os alunos adquiriram os conhecimentos que foram ministrados por seus mestres. Perrenoud (1999, p.146, grifo do autor) afirma que para mudar a avaliação não é coisa fácil, "para mudar as práticas no sentido de uma avaliação mais formativa, menos seletiva, talvez deva mudar a escola, pois a avaliação está no centro do sistema didático e do sistema de ensino".

0 uso do portfólio, principalmente no ensino superior, ainda é pouco explorado. Centra (1994 como citado em Alves, 2004, p.103) afirma que "o portfólio vem sendo apontado como uma das mais recentes contribuições para uma avaliação eficaz do ensino". Corroborando com esta afirmação, MacLaughlan e Mintz, citados ainda por Alves (2004, p.105), participam "que mais de 500 faculdades e universidades nos Estados Unidos começaram, a partir de 1990, a utilizar portfólios de ensino para a avaliação, tanto formativa quanto somativa".

O termo portfólio, originalmente vem do italiano "portafoglio", que significa "recipiente onde se guardam folhas soltas, e começou a ser empregado em artes plásticas, quando o artista fazia uma seleção dos seus trabalhos que exprimiam sua produção" (Torres, 2008, p.551). Sendo, portanto, uma coletânea ou conjunto de excertos seletos de diversos trabalhos. Exige, com isso, um planejamento cuidadoso por parte do aluno para determinar o que deve ou não conter em sua pasta, para que reflita ou evidencie as competências e/ou habilidades previstas no início do curso (Araújo \& Alvarenga, 2006, p.193).

O Portfólio é uma ferramenta pedagógica, que segundo Ambrósio (2013, p.24), "permite a utilização de uma metodologia diferenciada e diversificada de monitoramento e avaliação do processo de ensino e aprendizagem, não desviando a atenção da carga de efeitos inerentes à situação de aprendizagem". O que pode ser conceitualmente resumido por Sá-Chaves (1998 como citado em Ambrósio, 2013, p.25) como "um instrumento de construção de conhecimentos no processo ensino-aprendizagem". 
Fernandez (2001 como citado em Rangel, 2003, p.147) argumenta que o seu uso no ensino superior é um dos recursos possíveis, "pois coloca o aluno como responsável pelo seu processo de aprendizagem, favorecendo a postura reflexiva que envolva o reconhecer-se pensante e, ao mesmo tempo, um sujeito desejante". Nesse caminho, Vieira e De Sordi (2012) acreditam que o portfólio, no contexto da pedagogia universitária, é um procedimento de avaliação participativo entre professores e alunos.

No ensino superior, o seu uso deve ser tratado como meio e não como fim, e tratá-lo como inovação e não como novidade, exige do docente uma postura vigilante e participativa, implicando em alterar a compreensão de conhecimento e valorizar a capacidade produtiva do estudante (Vieira \& De Sordi, 2012). Assim exposto, Ambrósio (2013, p. 89) ratifica e concorda que é uma tentativa de "remarcar a ligação da avaliação com a importância de relações interativas, de trocas e negociações entre os sujeitos envolvidos com um determinado objeto".

\section{Óbices ao uso dos portfólios no ensino superior}

Algumas dificuldades foram levantadas para sua implementação no ensino superior, como retratou Bruzzi, Sá, Valls e Oliveira (2001) em três pontos principais: o impossível portfólio, alunos perdidos em sua elaboração; o portfólio como cronologia de vida, tendência de dividi-lo segundo uma cronologia de vida, relatando apenas o que de mais importante fizeram, sem autoavaliar; o portfólio como colcha de retalhos, sendo apenas os trabalhos significativos do aluno, sem nenhum desenvolvimento da construção do conhecimento.

Segundo Vieira e De Sordi (2012), o portfólio, na visão dos alunos, inicialmente se apresentou com as características de ser trabalhoso, resistente, adequado e complexo. Outro ponto realçado pelas autoras foi a compreensão que ficou de um fazer burocrático, ele não apresenta como um instrumento acabado e de fácil aplicação, pois ele exige planejamento, fundamentação teórica e preparo de alunos e professores.

Ponto realçado por Rangel, Nunes e Garfinkel (2006, p.179) foi o da sobrecarga do professor durante a experiência do uso do portfólio no curso de Odontologia da Universidade Estácio de Sá (UNESA), a partir de 2001. Os autores realçaram que o quantitativo de 30 alunos ou mais demandaram uma disponibilidade de tempo para um acompanhamento constante, "de forma a cumprir sua função informativa e de redirecionamento de estratégias, cujo potencial está na formação deste sujeito cidadão". 


\section{O uso do portfólio no ensino superior militar}

Todo o início de uma pesquisa requer uma motivação para o seu desenvolvimento, e em especial a sua relevância para a academia e para o campo em que o autor está trabalhando. Ao saber do uso do portfólio na EN, a inquietação por um melhor entendimento e o que existia do estado da arte dessa metodologia pedagógica, fez com que este autor fosse incialmente desenvolver uma pesquisa em três bancos de dados científicos da internet, o sítio do Banco de Teses da Capes, o Google Acadêmico e a Biblioteca Digital de Teses e Dissertações (BDTD), utilizando as seguintes

palavras-chave, respectivamente: "portfólio", "portfólio no ensino superior" e "portfólio no ensino superior militar". Os achados estão mostrados na tabela abaixo:

Tabela 1 - Número de documentos encontrados

\begin{tabular}{llll}
\hline Palavras-chave & Google & Capes & BDTD \\
\hline Portfólio & 65.800 & 215 & 664 \\
Portfólio + ensino superior & 21 & 7 & 35 \\
Portfólio + ensino superior militar & 0 & 0 & 0
\end{tabular}

Fonte: Internet. Elaboração própria.

Como se pode verificar, nenhum artigo, dissertação ou tese foi encontrado quando associamos o ensino superior militar ao uso do portfólio. Este fato constatado e a relevância em apresentar a experiência que foi realizada em uma IES militar para o meio acadêmico foi o que Alves (2004, p. 118), retratou em suas considerações finais sobre o uso dos portfólios como instrumentos de avaliação dos processos de ensinagem, que "experiências precisam ser divulgadas, publicadas e submetidas a críticas".

O currículo da EN, em 2014, contemplava uma disciplina denominada Cultura Organizacional Militar (COM), criada de modo a atender as necessidades surgidas com a admissão das Aspirantes do sexo feminino, no primeiro ano, para o Corpo de Intendentes da Marinha. A unidade de ensino 4, "O Sistema social militar na sociedade moderna", constante desta disciplina, possuía, dentre outros, o seguinte objetivo: "Descrever os programas e projetos sociais desenvolvidos pela Marinha do Brasil, junto ao seu público interno e no âmbito externo (população)".

Este tema estimulou a professora da disciplina a empregar uma técnica diferenciada e o portfólio foi considerado uma ótima opção para seu desenvolvimento e avaliação. A educadora já havia preparado um portfólio por ocasião de seu curso de mestrado e a experiência tinha sido interessante. Além 
disso, estudos consideram que a ferramenta possibilita a aquisição do conhecimento de forma processual e reflexiva, estimula a responsabilidade do discente pelo seu processo de aprendizagem, desperta a criatividade, dentre outras vantagens. 0 que é assegurado por Ambrósio (2013, p.24) ao afirmar que "o seu caráter compreensivo, de registro longitudinal, permite verificar dificuldades e agir em processo, no tempo da aprendizagem, ajudando ao estudante".

Inicialmente, a docente conversou com a turma e apresentou as orientações por escrito, onde constava uma explicação sobre o portfólio e seus benefícios, os objetivos da atividade e como a unidade de ensino seria desenvolvida, as atividades envolvidas, as responsabilidades dos grupos e o posicionamento da instrutora como orientadora de todo o processo. Expôs os critérios de avaliação, seus instrumentos e um cronograma de eventos. A avaliação constaria de uma média aritmética composta de três notas: uma da professora, outra da turma e por último a autoavaliação do discente.

Além das orientações, foram proferidas duas palestras sobre os programas e projetos sociais desenvolvidos no âmbito do Serviço de Assistência Social da Marinha (SASM), a primeira por um Oficial da Diretoria de Assistência Social da Marinha (DASM), e a segunda com o Capelão da EN, de modo a fornecer elementos e estimular ainda mais o estudo do tema. As Aspirantes participaram com perguntas e colocações, demonstrando interesse pelo assunto.

A proposta de elaboração do portfólio foi bem aceita pelas alunas e grupos no WhatsApp foram criados para acompanhamento, troca de experiência, sugestões e esclarecimentos, quase sempre em tempo real. Para os contatos gerais foi organizado um grupo com toda a turma. As orientações específicas foram fornecidas, de forma individual, para cada equipe, de modo a preservar as ideias de seus integrantes. Os trabalhos poderiam contemplar o mesmo conteúdo, mas a forma de apresentação seria diferenciada, de acordo com a criatividade, e isto era reservado. 0 uso do aplicativo telefônico de mensagens tornou o processo de estudo e construção do portfólio interativo e dinâmico. No dia da entrega dos portfólios, cada grupo fez a apresentação oral do tema em sala de aula. Em cumprimento às orientações da docente, quanto à necessidade da turma aproveitar todas as oportunidades para treinar falar em público, as voluntárias que apresentaram os trabalhos foram as aprendentes com mais dificuldades nessa habilidade, o que denota o interesse das mesmas em melhorar sua prática oral. Assim, mais um aspecto positivo foi verificado com a execução da atividade.

De maneira geral, os trabalhos elaborados, em formato de álbuns ilustrados com fotografias, pequenos textos e esquemas, foram de excelente qualidade, graças à dedicação e empenho das Aspirantes. O tema foi abordado de forma criativa e interessante por todas as equipes. A pesquisa foi realizada em diferentes fontes, incluindo entrevistas, sítios da internet, periódicos, 
revistas, boletins publicados pela Marinha etc. As alunas demonstraram encantamento com o trabalho social desenvolvido pela Força Armada em questão e isto, certamente, serviu de estímulo para prosseguirem na carreira militar. Dessa forma, além da aquisição de conhecimentos significativos para as suas carreiras e da oportunidade de estreitamento dos laços de amizade entre as integrantes da turma, o trabalho estimulou ainda mais o amor à profissão militar-naval.

É importante também destacar as principais dificuldades encontradas pelos grupos. A coleta de informações foi prejudicada por falta de facilidades de acesso à internet na instituição, houve também falta de tempo para o estudo do tema, reuniões e entrosamentos para tomada de decisão, confecção do álbum e para preparação da apresentação oral do trabalho. Sabese que os Aspirantes da EN têm uma rotina atribulada, principalmente os do primeiro ano, e isto compromete o cumprimento das tarefas escolares propostas para fora de sala de aula. Assim, é preciso analisar com cuidado todas as variáveis que podem servir de entraves à consecução de atividades desse tipo por parte dos discentes. A instituição precisa disponibilizar meios que facilitem a adoção, pelo professor, de novas técnicas de aprendizagem e avaliação.

Finalizando, a professora destaca que, considerando todos os entraves e os aspectos positivos com a realização do trabalho, usaria a ferramenta portfólio como metodologia e avaliação da aprendizagem. Com o intuito de aprimorar o processo de elaboração do trabalho, por parte dos grupos, solicitaria autorização para as Aspirantes usarem a biblioteca no horário das aulas da disciplina, para reuniões e pesquisas na internet, com a supervisão da docente. Para tanto, os computadores do local deveriam ter o acesso liberado.

\section{Considerações Finais}

O ensino superior militar é considerado de qualidade, porém ainda utiliza a avaliação somativa, excludente e hierarquizadora, tendo as provas e testes como ferramentas de aferição do aprendizado dos seus alunos, classificando-os e certificando-os ao final da graduação com os seus respectivos diplomas de bacharéis, qualificando-os a exercerem atividades dos "homens das armas". Os seus docentes são profissionais qualificados e que têm numa relação de força e poder perante o seu aprendente, caracterizada pelo seu juízo de valor.

A avaliação formativa é interessante na medida em que o aluno se torna o centro do processo de ensino e aprendizagem, e tem como parceiro o seu professor, no que se convencionou chamar de contrato didático. Ensinar, como relatado, não é apenas uma mera transferência de conhecimentos de uma pessoa mais velha para uma mais nova, é muito mais. É incitar o aprendente, motivá-lo para que se sinta parte da relação dialógica criada, que culminará com a reflexão, com a autoavaliação e com o seu crescimento como pessoa socialmente incluída. 
A experiência do uso do portfólio como metodologia de aprendizagem e avaliação pedagógica de um pequeno grupo de Aspirantes do primeiro ano da Escola Naval foi muito importante. Procurou-se uma alternativa inovadora no trato da relação professor-aluno e mais especificamente no ensino e aprendizagem. A docente ousou, desafiou e estimulou suas alunas a construírem conhecimento a partir da pesquisa, da discussão, da relação coletiva, por intermédio de seus trabalhos.

O uso do portfólio, como estratégia inovadora e efetiva de avaliação formativa, ainda não está muito estudado e difundido no Brasil. Porém, com o que pode ser verificado, tanto na experiência realizada em uma IES militar quanto nos achados acadêmicos em artigos e livros sobre o foco do ensino superior, pode-se apontar, mesmo que sejam achados iniciais e acanhados, que o uso do portfólio tenta combater a inércia de procedimentos e avaliações excludentes e classificatórias, procura caminhar num ambiente de aprendizagem propício para a construção do conhecimento. É importante reforçar a emancipação e ampliação da autonomia discente, acompanhada lado a lado pela parceria do educador.

\section{Referências}

Alves, L. P. (2004). Portfólios como instrumentos de avaliação dos processos de ensinagem. In L. das G. C. Anastasiou \& L. P. Alves (Orgs.), Processos de ensinagem na universidade: Pressupostos para as estratégias de trabalho em aula (3a ed.) (pp. 101-120). Joinville, SC: Ed.UNIVILLE.

Ambrósio, M. (2013). 0 uso do portfólio no ensino superior (2a ed.). Petrópolis, RJ: Vozes.

Anastasiou, L. das G. C. (2004). Ensinar, aprender, apreender e processos de ensinagem. In L. das G. C. Anastasiou \& L. P. ALVES (Orgs.). Processos de ensinagem na universidade: Pressupostos para as estratégias de trabalho em aula (3a ed.) (pp.11-38). Joinville, SC: Ed.UNIVILLE.

Araujo, Z. R. \& Alvarenga, G. M. (2006, setembro/dezembro). Portfólio: uma alternativa para o gerenciamento das situações de ensino e aprendizagem. Estudos em Avaliação Educacional, 17(35), 187-210.

Lei n. 9.394, de 20 de dezembro de 1996. (1996, 23 de dezembro). Estabelece as Diretrizes e Bases da Educação Nacional. 1996. Diário Oficial da União, seção1.

Bruzzi, R. C. V., Sá, A. V. M., Valls, R. P. \& Oliveira B. C. de (2001, julho/dezembro). Auto-avaliação no ensino superior: um espelho chamado portfólio. Linhas críticas, Brasília, DF, 7(13), 289-303. $\begin{array}{lllll}\text { Recuperado em } & 17 & \text { maio } & 2016, & \text { de }\end{array}$ http://periodicos.unb.br/index.php/linhascriticas/article/view/6543

Chueiri, M. S. F. (2008, janeiro/abril). Concepções sobre a avaliação escolar. Estudos em Avaliação Educacional, 19(39), 49-64.

Gatti, B. A. (2003, janeiro/junho). O professor e a avaliação em sala de aula. Estudos em Avaliação Educacional, 27, 97-114. 
Gil, A. C. (2009). Métodos e técnicas de pesquisa social (6a ed.). São Paulo: Atlas.

Hadji, C. (2001). A avaliação desmistificada. Porto Alegre: Artmed.

$\begin{array}{llll}\text { Ivenicki, A. \& Canen, A. (2016). Metodologia da Pesquisa: rompendo } & \end{array}$ fronteiras curriculares. Rio de Janeiro: Ciência Moderna.

Libâneo, J. C. (2005). As Teorias Pedagógicas Modernas Revisitadas pelo Debate Contemporâneo na Educação. In J. C. Libâneo \& A. Santos (Orgs.). Educação na era do conhecimento em rede e transdisciplinaridade (Cap.1). Campinas, SP: Alínea, 16-58.

Luckesi, C. C. (2011). Avaliação da aprendizagem: componente do ato pedagógico. São Paulo: Cortez.

Perrenoud, P. (1999). Avaliação: da excelência à regulação das aprendizagens - entre duas lógicas (P.C. Ramos, trad.). Porto Alegre: Artmed.

Rangel, J. N. M. (2003, julho/dezembro). 0 portfólio e a avaliação no Ensino Superior. Estudos em Avaliação Educacional, 28, 145-160. Recuperado em 17 maio 2016, de http://www.fcc.org.br/pesquisa/publicacoes/eae/arquivos/1148/1148.pdf

Rangel, J. N. M., Nunes, L. C. \& Garfinkel, M. (2006, setembro/dezembro). 0 portfólio no ensino superior: práticas avaliativas em diferentes ambientes de aprendizagem. Pro-posições, 17(3), 167-180. Recuperado em 17 maio 2016, de http://periodicos.sbu.unicamp.br/ojs/index.php/proposic/article/view/8643614

Torres, S. C. G. (2008, maio/agosto). Portfólio como instrumento de aprendizagem e suas implicações para a prática pedagógica reflexiva. Revista Diálogo Educacional, Curitiba, 8(24), 549-561. Recuperado em 17 maio 2016, de www2.pucpr.br/reol/index.php/dialogo?dd99=pdf\&dd1=2040

Vieira, M. L. \& De Sordi, M. R. L. (2012, abril). Possibilidades e limites do uso do portfólio no trabalho pedagógico no ensino superior. Revista e-curriculum, São Paulo, 8(1), 1-27. Recuperado em 17 maio 2016, de http://revistas.pucsp.br/index.php/curriculum/article/view/9044 